\title{
LAS EPOPEYAS HOMÉRICAS EN LA NUMISMÁTICA CLÁSICA
}

\section{Francisco Salinas y Wilson Peres}

\section{INTRODUCCION}

T a numismática es la disciplina que estudia las monedas y medallas, especialmente las antiguas; por ello, es una rama auxiliar de la arqueología y la historia.

Inicialmente el comercio se realizaba mediante el trueque, el que presentaba numerosas dificultades: encontrar a quien tuviera lo que uno necesitaba y que requiriera lo que uno podía ofrecer, indivisibilidad de los bienes ofrecidos para poder canjearlos por otros objetos de menor valor y el carácter perecible de los bienes ofrecidos y, por ende, la pérdida de su valor de canje.

Para hacer posible el trueque, diversos pueblos encontraron bienes de amplia aceptación, divisibles y poco perecibles, que eran aceptados universalmente en canje por los otros bienes. Entre ellos se contaron ciertos tipos de conchas marinas, el ganado, la sal, las piedras horadadas entre los pueblos originarios chilenos, los granos de cacao en Mesoamérica y los metales. Estos últimos resolvían de buena manera los problemas enumerados y se emplearon en Egipto, Mesopotamia y el mundo celta bajo la forma de polvo, barras y brazaletes. Presentaban, sin embargo, el inconveniente de deber ser pesados y verificada la pureza del metal antes de cada transacción.

La solución fue la moneda, es decir piezas de metal cuyo peso y pureza eran garantizados por la autoridad. Las primeras fueron acuñadas en Lidia (Asia Menor) a finales del siglo VII a.C., en electro, una aleación de 70\% a $80 \%$ de oro y de $30 \%$ a $20 \%$ de plata, con pequeñas trazas de cobre, que se encuentra en estado natural en esa región, especialmente en depósitos aluviales en el río Pactolo.

Ya en el reinado de Creso, último monarca independiente de Lidia (560-547 a.C.) hubo acuñaciones diferenciadas de oro y plata. Muy pronto la moneda fue adoptada por las islas griegas como Egina, el imperio persa, las ciudades de la Grecia continental, las colonias griegas, especialmente de la Magna Grecia y Sicilia, y los restantes pueblos del mundo mediterráneo y celta. 
Surgieron sistemas monetarios con una unidad base, múltiplos y piezas divisionarias. Los más importantes fueron los derivados de la estátera y el dracma, con diversos valores locales que fueron confluyendo en unos pocos para facilitar el comercio entre las ciudades. Las acuñaciones en bronce y cobre nacieron en el mundo griego y son algo más tardías (siglo V a.C.) e incluían unidades como el chalkon ático, equivalente a 1/8 de óbolo (pequeña moneda de plata que valía $1 / 6$ de dracma).

Las monedas fueron confeccionadas mayoritariamente por acuñación, colocando un dado metálico con algún diseño en un yunque. Sobre él se colocaba con tenazas una pieza de metal caliente en forma de lenteja, producida por fundición y del peso requerido. Sobre ella se colocaba un cuño con el diseño deseado y se martillaba el cuño contra ella hasta que el diseño quedaba estampado en la moneda. La pieza se colocaba caliente para que fuera más dúctil al golpe. Inicialmente el dado colocado en la base tenía alguna forma sin mayor importancia, teniendo solo el efecto de ayudar a que el diseño del cuño puesto sobre la pieza penetrara en ella con los golpes. Así se produjeron las llamadas monedas incusas. Más tarde se fabricaron dados con diseños elaborados, produciéndose monedas con anversos y reversos. Hubo escasas monedas fabricadas por fundición.

Inmediatamente las autoridades de ciudades y reinos se percataron de que las imágenes de sus monedas podían ser símbolos de la autoridad real o local, tales como las divinidades protectoras de las ciudades, la heráldica de dinastías y reyes, o los productos característicos de cada comunidad. También se mostraron los orígenes mitológicos de las ciudades, sus templos célebres, su armamento característico o sus elementos náuticos. En el reinado de Alejandro Magno y el posterior período helenístico aparecen retratos de los reyes en los anversos de muchas de las monedas. En términos estrictos, las acuñaciones griegas autónomas duran hasta la captura de Egipto por Augusto en el 30 a.C.

Por su parte, la moneda romana, tras estar constituida por lingotes y monedas fundidas (aes rude, aes signatum y aes grave, sucesivamente) a comienzos del siglo III a.C., derivó a piezas de plata de peso semejante al dracma llamadas denarios. Desde el 289 a.C. se nombraban anualmente tres funcionarios a cargo de la acuñación, los tresviri monetalis. ${ }^{1}$ Estos colocaban en las monedas imágenes religiosas, históricas, simbólicas, arquitectónicas e incluso algunas relacionadas con sus propias familias.

1 Su título completo era triumviri o tresviri aere argento auro flando feriundo (tres hombres encargados de la fundición y acuñación en bronce, plata y oro). El adjetivo monetalis proviene del hecho de que la ceca de Roma estaba cerca del templo de Juno Moneta (la consejera o la solitaria). 
En la época imperial, se estandarizó un sistema monetario con áureos (piezas de oro), denarios (de plata) y sestercios (1/4 de denario), dupondios (dos ases) y ases en bronce y cobre. Al partir de comienzos del siglo III d.C., el sistema se fue erosionando por la inflación y la inestabilidad política durante los emperadores militares y del Bajo Imperio. Se redujo la acuñación en plata y las emisiones se concentraron en una nueva pieza de oro (el sólido) y piezas de cobre o bronce (follis). Este segundo sistema duró hasta la reforma monetaria del emperador Anastasio del 498 d.C., con cuyas acuñaciones se inaugura la numismática bizantina.

En todos los períodos de las acuñaciones imperiales romanas, la norma era colocar la imagen del emperador o de miembros destacados de su familia en el anverso con sus títulos y poderes (imperator, césar, padre de la patria, potestad de tribuno, cónsul o dominus nostrum, después de Constancio II). Los reversos podían ser religiosos, de alabanza al emperador o su familia, dinásticos, arquitectónicos o históricos, entre otros.

Dado que gran parte de la sección oriental del imperio hablaba griego, no latín, las monedas de las ciudades de esa extensa área tenían sus textos en griego y reversos ligados a la religión, arquitectura y tradición locales, aunque frecuentemente mantenían la efigie del emperador en el anverso. Estas monedas, que suelen ser llamadas provinciales romanas o, menos correctamente, griegas imperiales, se acuñaron hasta el cierre de la última ceca provincial, la de Alejandría, por Diocleciano en el 297 d.C. Por otra parte, diversas regiones y ciudades (por ejemplo, Atenas) mantuvieron un sistema de acuñación en bronce casi autónomo, en el que no era obligatorio el busto imperial en el anverso.

Naturalmente, las imágenes en las monedas evolucionaron estilísticamente del mismo modo en que lo hizo la estatuaria, la pintura de vasos cerámicos, la pintura, el mosaico y la glíptica, encontrándose piezas en los estilos arcaico, severo (o clásico inicial), clásico, helenístico, romano y romano tardío, con sus respectivas etapas.

Este es resumidamente el mundo de más 1100 años de la moneda antigua en el que hemos investigado la presencia de las epopeyas homéricas. El trabajo se divide en siete secciones. Luego de esta introducción, en la segunda sección se presentan las monedas con imágenes de dioses y semidioses mencionados en la Ilíada y la Odisea. En la tercera, se muestran monedas con imágenes de Homero y de la musa de la poesía épica, Calíope. En la cuarta, piezas que se refieren a hechos vinculados a Troya, pero anteriores a la guerra. En la quinta, monedas con figuras de héroes, primero aqueos y luego troyanos. En la sexta sección, se presenta piezas que ilustran otros hechos vinculados a las dos epopeyas. En la séptima, se concluye. 


\section{II.-DIOSES Y SEMIDIOSES}

\section{AFRODITA}

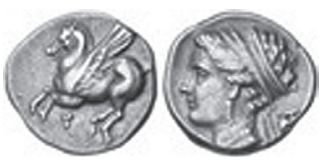

Corinto (Peloponeso), AR dracma, 350-300 a.C. 15 mm, 2,78 g. ${ }^{2}$

Pegaso volando hacia la izquierda. Abajo, letra koppa. Rx: Cabeza de Afrodita mirando a la izquierda, cabello tomado con una banda.

Afrodita triunfa en el juicio de Paris, por lo que toma partido por los troyanos. Amante de Anquises y madre de Eneas. Salva a Eneas de Diomedes que la hiere. En la Odisea, en la tierra de los feacios, el bardo Demódoco canta como ella engañó a su marido Hefesto con Ares.

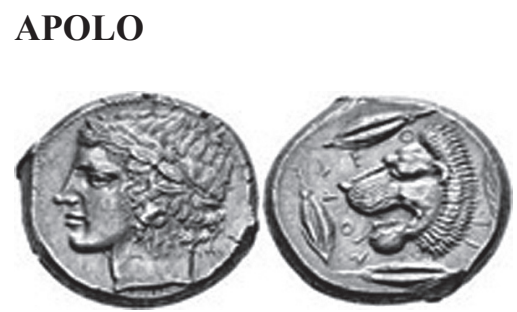

Leontinoi (Sicilia), AR tetradracma, 455-430 a.C., 23,5 mm, 17,4 g.

Cabeza de Apolo laureada, mirando a la izquierda. Rx: $\Lambda$ EONTINOI. Cabeza de león mirando a la izquierda rodeado de tres granos de cebada y una hoja de laurel.

La hoja de laurel es identificada como la firma del grabador conocido como el maestro della foglia.

En la Ilíada, Apolo arroja flechas de la peste sobre el campamento aqueo y ayuda a Héctor a matar a Patroclo. Posteriormente, ayuda a Paris a matar a Aquiles guiando la flecha hacia su talón.

$2 \quad$ El anverso de las monedas se describe primero; luego el reverso, indicado mediante Rx. Se usa la convención numismática de que AE significa bronce; AR, plata y $\mathrm{AU}$, oro. El tamaño de las imágenes en este artículo no se corresponde con el tamaño de las monedas. 


\section{ARES}

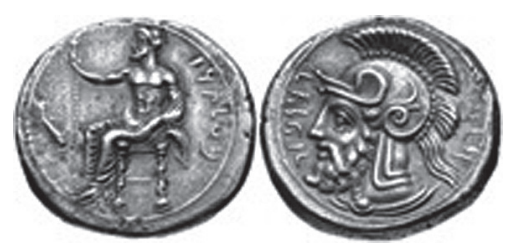

Tarsos (Cilicia), AR estátera, 380-373 a.C. (época de Farnabazo), 23 mm, $10,37 \mathrm{~g}$.

Baal de Tarsos sentado mirando a la izquierda, con cetro. Rx: Ares, con barba y casco ático.

En la Ilíada, Ares participó en uno y otro bando. Combatió junto a Héctor contra Diomedes. En la Odisea, se le menciona como amante de Afrodita.

\section{ARTEMISA}

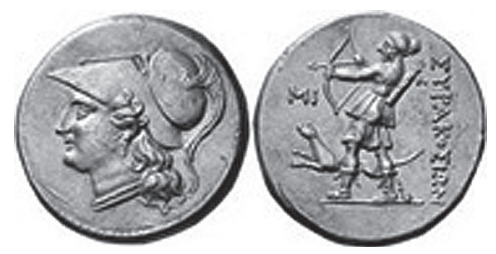

Siracusa (Sicilia), AR 12 litras (equivalente a dos dracmas), 214-212 a.C. (quinta democracia), $24 \mathrm{~mm}, 10,16 \mathrm{~g}$.

Cabeza de Atenea mirando a la izquierda, portando casco corintio con penacho. Rx: $\Sigma$ rPAKO $\Sigma \mathrm{I} \Omega \mathrm{N}$. Artemisa con su arco, caminando a la izquierda junto a su perro de caza.

Partidaria de los troyanos como su hermano Apolo, detuvo los vientos inmovilizando la flota aquea en la Áulide. En la Odisea, mata a Ariadna, amada por Dionisio. 


\section{ATENEA}

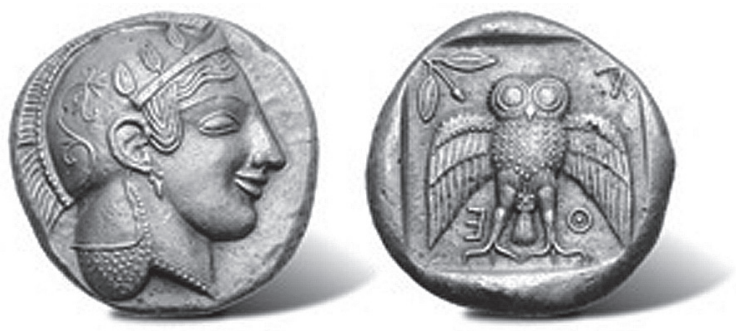

Atenas (Ática) AR decadracma, 467-465 a.C., 34 mm, 43,38 g.

Cabeza de Atenea a la derecha, con aros, collar y casco con hojas de olivo.

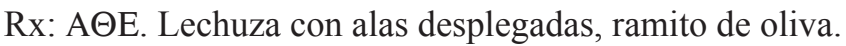

Derrotada en el juicio de Paris toma partido por los aqueos. En la Odisea, protege a Ulises.

\section{AURORA}

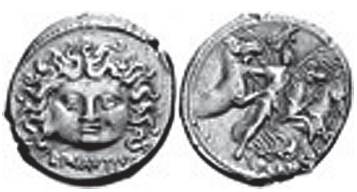

República Romana, L. Plautius Plancus, AR denario, 47 a. C., 18 mm., 3,75 g.

L PLAVTIVS Cabeza de Gorgona, Rx: PLANCVS, Aurora alada con ramo de palma, conduciendo los caballos del Sol.

La Aurora es citada continuamente en la Ilíada y en la Odisea, marcando el inicio de un nuevo día. 


\section{DIONE}

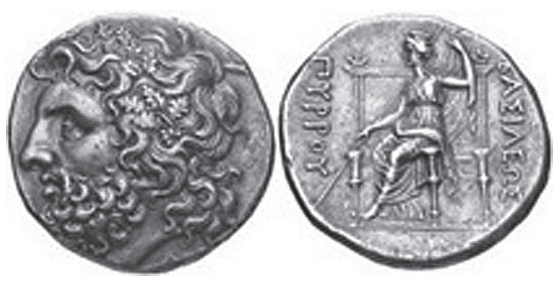

Epiro (reinado de Pirro), AR tetradracma, 295-272 a.C., 27 mm, 16,5 g. Cabeza de Zeus mirando a la izquierda, con corona de hojas de roble.

Rx: BA $\Sigma \Lambda$ E $\Omega \Sigma$ ПTPPOr. Dione, madre de Afrodita, sentada mirando a la izquierda, con cetro.

\section{DIONISOS}

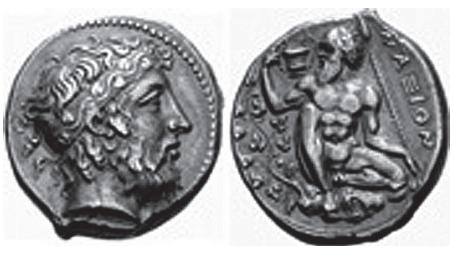

Naxos (Sicilia), AR tetradracma, 430-420 a.C., 24 mm, 17,16 g.

Cabeza barbada de Dionisos mirando a la derecha. Rx: NA $\Xi I O N$. Sileno desnudo bebiendo de un cántaro.

En la Ilíada, se cuenta su disputa con el rey Licurgo de Tracia y, como tras la muerte de este, devolvió su fertilidad a la tierra. 


\section{ESCILA}

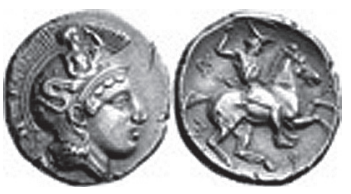

Farsalia (Tesalia), AR dracma, c. 380-450 a.C., $18 \mathrm{~mm}, 6,08 \mathrm{~g}$.

Cabeza de Atenea mirando a la derecha. Casco adornado con imagen de Escila. Rx: $Ф A P \Sigma$. Jinete tesalio galopando a la derecha, con petasos.

En su regreso, Odiseo opta por pasar con su barco cerca de Escila, monstruo de seis cabezas, perdiendo a seis de sus marineros que ella arrebata, evita así la destrucción total de su nave y su tripulación por Caribdis.

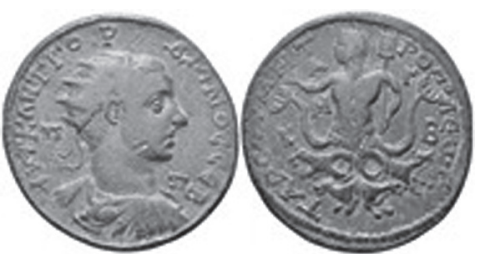

Tarso (Cilicia). AE Gordiano III. 238-244 d.C. 37mm 26.85 g. ArT M ANT $\Gamma O P \triangle I A N N O \Sigma \Sigma E B$. Busto hacia la derecha.

Rx: TAP $\Sigma O \Upsilon$ MHTPOПO $\Lambda$ E $\Omega \Sigma$ A $\Gamma$ B K M Escila de frente, cabeza hacia la izquierda, sosteniendo un timón; su bajo cuerpo compuesto por dos colas de delfín y cuatro cabezas de perro. 


\section{HADES}

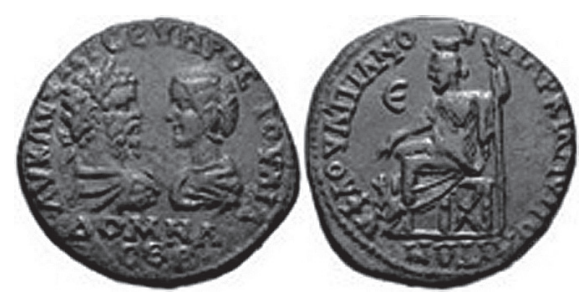

Marcianópolis (Moesia inferior), AE 5 assaria (2,5 óbolos). 193-211 d.C., 28 $\mathrm{mm}, 11,38 \mathrm{~g}$.

Ar K $\Lambda \Sigma$ EП $\Sigma$ EYHPO $\Sigma$ IOr $\Lambda$ IA $\Delta$ OMNA $\Sigma$ EB

Cabezas enfrentadas de Septimio Severo y Julia Domna.

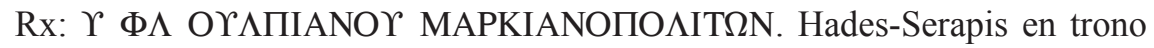
junto a Cerbero (con dos cabezas).

En la Ilíada se narra que Hades, Zeus y Poseidón se repartieron los mundos, correspondiéndole al primero el inframundo. En la Odisea, Ulises desciende al reino de Hades para pedir la ayuda del adivino Tiresias.

\section{HEFESTO}
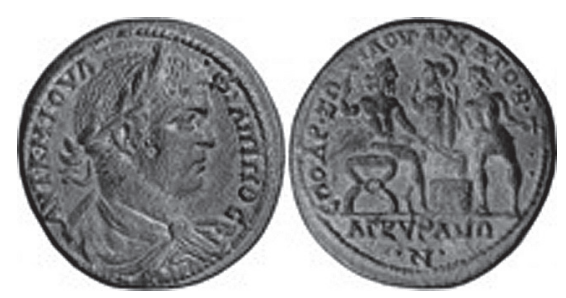

Ancyra (Frigia). Filipo I, el árabe. 244-249 d.C. AE, 35mm 16.63 g.

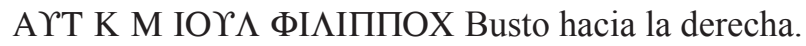

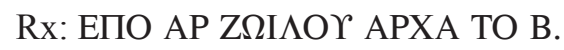

$\mathrm{Rx}$ : AГKrPAN $\Omega \mathrm{N}$, en exergo. Hefestos y cíclope trabajando en la armadura de Aquiles. Atenea observa.

En la Ilíada, fabrica nuevas armas para Aquiles a pedido de Tetis. 


\section{HERA}
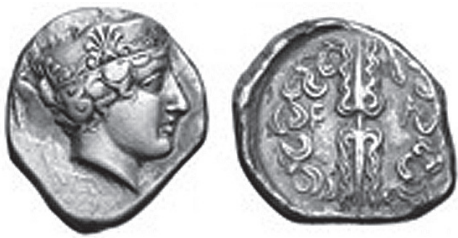

Olimpia (Elis), AR estátera, 420 a.C. (90a Olimpíada), 24 mm, 12,5 g.

Cabeza de Hera con corona ornamentada, mirando a la derecha. Rx: F-A (digamma alfa). Rayo flamígero de Zeus dentro de una guirnalda de hojas de olivo.

Derrotada en el juicio de Paris, Hera odia a los troyanos; engaña a Zeus para favorecer a los aqueos.

\section{HERMES}
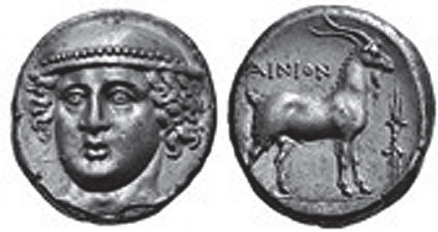

Ainos (Tracia), AR tetradracma, 360-350 a.C., 24,5 mm.,15,29 g.

Cabeza de Hermes con petasos, de frente. Rx: AINION. Cabra mirando a la derecha, rayo.

En el comienzo de la Ilíada, Hermes figura como aliado de los aqueos contra los troyanos. Sin embargo, por instrucción de Zeus ayuda a Príamo a llegar a la presencia de Aquiles para rescatar el cuerpo de Héctor. Ayuda a Odiseo a escapar de Circe dándole unas hierbas. Informa a Calipso que los dioses han decidido que permita el retorno de Odiseo a su hogar. 


\section{IRIS}

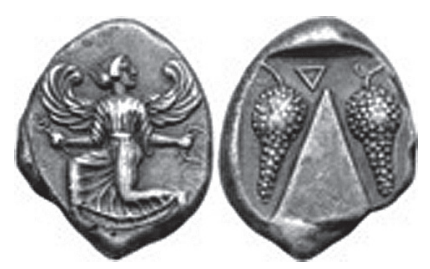

Kaunus (Caria), AR estátera, 430-410 a.C., 25 mm, 11,58 g.

Iris (alada) corriendo hacia la izquierda. Rx: Meteoro triangular entre dos racimos de uva, $\Delta$ invertida.

Aparece en la Ilíada como mensajera de los dioses.

\section{LETO}

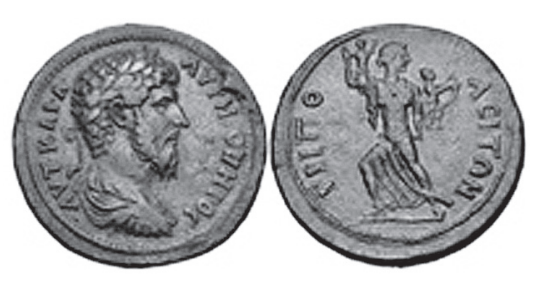

Trípoli (Lidia), 161-169 d.C., AE medallón, 36 mm.

ArT KAI $\Lambda$ ArPH OrHPO $\Sigma$. Cabeza de Lucio Vero, laureado, mirando a la derecha.

Rx: TPIПO $\Lambda E I T \Omega N$. Leto avanzando hacia la izquierda, llevando dos niños, tal vez sus hijos Apolo y Diana.

Se la menciona en la Ilíada en tanto madre de Apolo. 


\section{POSEIDÓN}

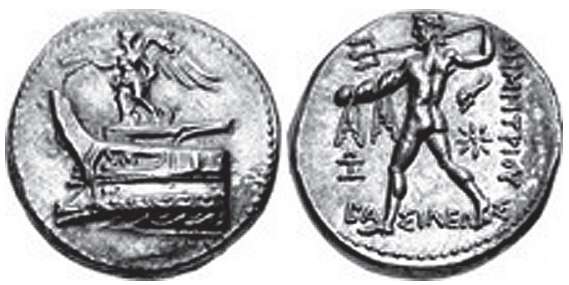

Macedonia (reinado de Demetrio I Poliorcetes), AR tetradracma, 306-283 a.C., $27,5 \mathrm{~mm}, 17,11 \mathrm{~g}$.

Nike, sobre la proa de una galera, tocando trompeta hacia la izquierda. Rx: BA $\Sigma I \Lambda E \Omega \Sigma \Delta$ HMHTPIOr. Poseidón Pelagaios mirando a la izquierda, preparándose para arrojar su tridente.

Poseidón apoya a los aqueos pues Laomedonte, padre de Príamo, no le recompensó su ayuda para construir las murallas de la ciudad. Después se irrita con los aqueos por su impiedad y dispersa sus barcos cuando regresaban a sus hogares. En la Odisea, persigue a Ulises por haber cegado a su hijo Polifemo.

\section{SIRENAS}

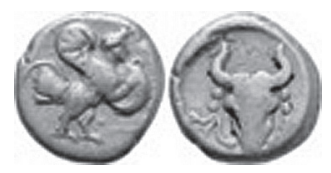

Jonia, electrón, hemihekte, siglo $\mathrm{V}$ a.C., $9 \mathrm{~mm}, 0,94 \mathrm{~g}$.

Sirena tocando tympanon (tamborín), a la derecha. Rx: bucráneo

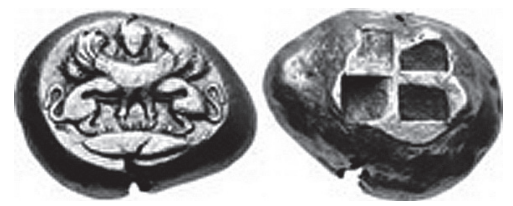

Cícico (Misia), electrón, estátera, 550-450 a.C., 19,5 mm, 16, 9 g.

Sirena de cuerpo doble. Rx: cuadrado incuso de cuatro partes.

En la Odisea, para no perecer atraído por su canto, Odiseo hace que sus compañeros taponen sus oídos con cera y lo aten al mástil de pies y manos. 


\section{TETIS}

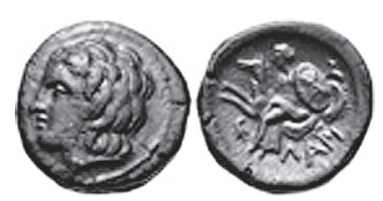

Larissa Cremaste (Tesalia), AE trichalkon (1/24 de dracma), siglo IV a.C., $18 \mathrm{~mm}, 7,4 \mathrm{~g}$.

Cabeza de Aquiles mirando a la izquierda. R: $\Lambda$ API Tetis sobre un hipocampo, sosteniendo el escudo de Aquiles con su monograma AX.

En la Ilíada, Tetis aparece como madre de Aquiles. Casada con Peleo, rey de los Mirmidones.

\section{ZEUS}

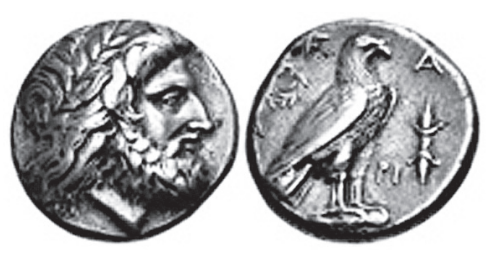

Olimpia (Elis), AR estátera. 276-260 a.C. (126-130 Olimpíada), 22.5mm, $12.10 \mathrm{~g}$.

Cabeza de Zeus laureada, mirando a la derecha. Rx: FA (digamma alfa) águila sobre capitel jónico; en la derecha, rayo; en la izquierda, guirnalda.

Como dios supremo, aparece continuamente tanto en la Ilíada como en la Odisea. 


\section{III.- Homero y la musa}

\section{HOMERO}

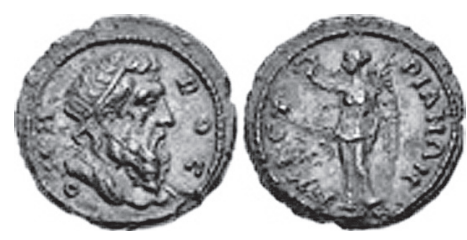

Amastris (Paflagonia). ca. 138-192 d.C. AE triassarion (1,5 óbolos). 22mm. OMHPO $\Sigma$. Cabeza de Homero hacia la derecha. Rx: AMAXTPIAN $\Omega N$. Victoria hacia la derecha.

\section{CALÍOPE, MUSA DE LA POESÍA ÉPICA}

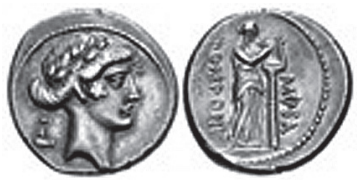

República Romana, Q. Pomponius Musa. 56 a.C.

AR denario (18mm, $3.76 \mathrm{~g})$.

Cabeza de Apolo con corona de laurel hacia la derecha, clave de lira a la izquierda. Rx: MUSA POMPONI. Calíope, con una túnica larga y peplo, de pie mirando a la derecha, tocando lira colocada sobre una columna.

La gens Pomponia fue una familia de plebeyos en la República y en tiempos imperiales hasta fines del siglo III d.C. Hacia el fin de la República, reclamaron su descendencia de Pompo, un hijo de Numa Pompilio. Sus monedas atestiguan los cognomina Molo, Musa, y Rufo; pero no el más importante, Matho. Q. Pomponio Musa fue un magistrado, tresvir monetalis y banquero que vivió en el siglo I a.C. Jugando con las palabras, acuñó diez tipos de denarios: uno para cada una de las musas y otro con la imagen de Hércules y la inscripción HERCULES MUSARUM. 


\section{IV.- Fundación de Troya y hechos previos a la guerra}

\section{ILO, HIJO DE TROS}

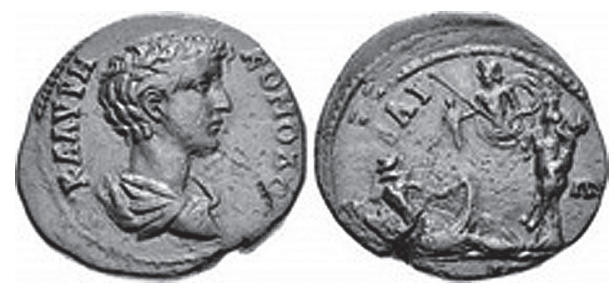

Ilión (Tróade). Cómodo. Como césar, 166-177 d.C. AE (30mm, 14.37 g). $\mathrm{K} \Lambda \mathrm{A}$ (PPH KOMO $\Delta \mathrm{O} \Sigma$. Busto hacia la derecha. Rx: I $\Lambda \mathrm{IE} \Omega$ N. Ilo (fundador legendario de Troya) reclinado hacia la derecha, mirando a Zeus que desciende del cielo sosteniendo el Paladio en la mano derecha y cetro en la izquierda; a la derecha, vaca colgada de un árbol siendo sacrificada por un hombre que toma un cuerno con la mano izquierda y tiene un cuchillo de sacrificio en la derecha.

Ilo recibió una vaca como premio por vencer en una competencia de lucha y fue instruido de fundar una ciudad donde la vaca se echara a descansar, lo que sucedió en Ilión. Después de que pidiera un signo a Zeus, apareció el Paladio, al que sacrificó la vaca (Apolodoro 3.12.2-3).

\section{ILO SACRIFICA UNA VACA A ATENEA ILIAS (EL PALADION)}
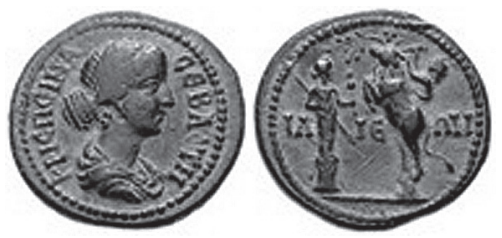

Ilión (Tróade). Crispina, esposa de Cómodo. Murió en el 183 d.C. AE $28 \mathrm{~mm}$ (11.89 g). КПI $\Sigma \Pi E I N A \Sigma E B A \Sigma T H$, busto hacia la derecha. Rx: I $\Lambda$-IE- $\Omega$ N, Ilo de pie hacia la izquierda, sacrificando un toro ante estatua de Atenea Ilias (el Paladio) que mira hacia la derecha. 


\section{GANIMEDES, HIJO DE TROS, HERMANO DE ILO}

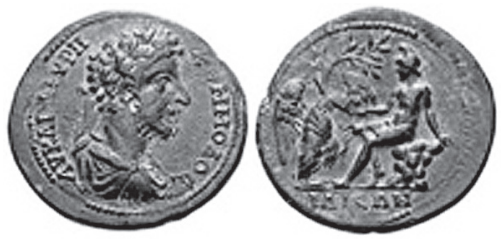

Ilión (Tróade). Cómodo. 174-177 d.C. AE, 31mm, 14.22 g.

ArT KAI M ArPH KOMMO $\Delta \mathrm{O} \Sigma$ Busto a la derecha. Rx: I $\Lambda$ IE $\Omega N$. Ganimedes, con gorro frigio, sentado sobre unas rocas y dando una copa a un águila que la toma con su garra izquierda y bebe de ella; atrás, árbol.

\section{POSEIDÓN Y APOLO CONSTRUYEN LAS MURALLAS DE TROYA}

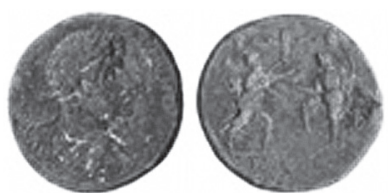

Ilión (Tróade). Marco Aurelio, 161-180 d.C. 34mm, 26.54g.

Busto hacia la derecha. Rx: Poseidón aplicando mezcla a un ladrillo sostenido por Apolo; atrás, murallas de Troya.

\section{ESCAMANDRO}
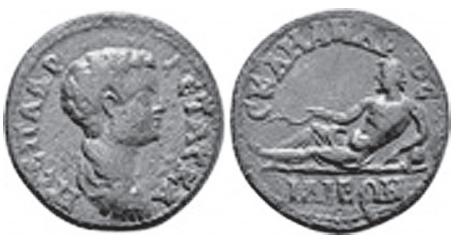

Ilión (Tróade). Geta (César, 198-209 d.C.). AE 23mm, 8.44g.

$\Pi \Sigma$ ЕП AYP ГЕТА $\Sigma$ AE. Busto hacia la derecha. Rx: $\Sigma$ KAMAN $\Delta \mathrm{PO} \Sigma$ I $\Lambda$ IE $\Omega$ N. Río Escamandro reclinado hacia la izquierda. 


\section{PRÍAMO}

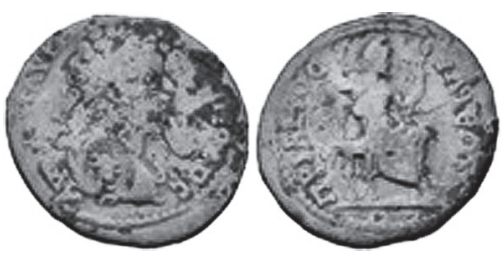

Ilión (Tróade). Cómodo. 177-192 d.C. AE. Acuñada ca. 180-182 d.C. 27mm, $10.64 \mathrm{~g}$.

AYT ---AYPH --- MO $\Delta \mathrm{O} \Sigma$ Busto hacia la derecha, con contramarca de cabeza de Atenea hacia la derecha en óvalo incuso. Rx: ПPIAMO $\Sigma$ I $\Lambda$ IESN. Príamo con gorro frigio sentado en el trono hacia la derecha, sosteniendo cetro.

\section{EL JUICIO DE PARIS}

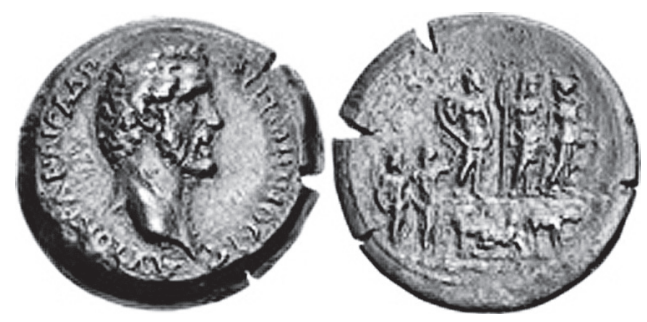

Alejandría (Egipto) Antonino Pio, 138-161 d.C. AE dracma, 35 mm, 23.14 g. LZ significa año real $7=143 / 4$ d.C.

A TTOKPA K AI $\Lambda$ A $\triangle$ P ANTSNINNO $\Sigma \Sigma$. Busto de Antonino Pío hacia la derecha. RX: L Z Juicio de Paris: a la derecha, sobre una plataforma, Afrodita, Hera y Atenea de pie con sus atributos habituales; a la izquierda sobre el suelo, debajo de un árbol, Paris hacia la derecha; adelante, Hermes mirando a Paris y apuntando a Afrodita con la mano izquierda; frente a la plataforma, varios animales; arriba, dos erotes sosteniendo una guirnalda. 


\section{V.- Héroes de la Ilíada y la Odisea}

\section{Aqueos}

\section{AQUILES}

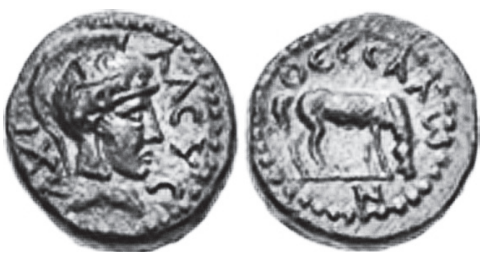

Tesalia, Comunidad de Tesalia. Época de Adriano. 117-138 d.C. AE assarion (1/2 óbolo). $13 \mathrm{~mm}$.

$\mathrm{A} \Xi \mathrm{I} \Lambda \Lambda \mathrm{E} \Gamma \Sigma$ Cabeza de Aquiles con casco hacia la derecha. Rx: $\Theta E \Sigma \Sigma \mathrm{A} \Lambda \Omega \mathrm{N}$ Caballo pastando hacia la derecha.

\section{ODISEO}

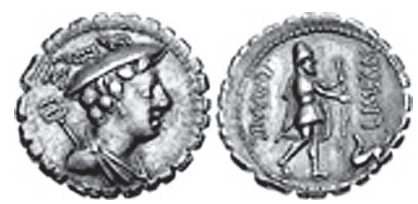

República Romana. C. Mamilius Limetanus. 82 a.C. AR Denario serrado, $19 \mathrm{~mm}, 4.10 \mathrm{~g}$.

Cabeza de Mercurio hacia la derecha, con petasos alado; a la izquierda M sobre caduceo.

Rx: C MAMIL hacia abajo a la izquierda, LIME(TA)N hacia arriba a la derecha. Ulises, con píleo y ropa de marinero, caminando hacia la derecha, con bastón en la mano izquierda y extendiendo su mano derecha hacia Argos que avanza hacia él.

Los Mamilii eran una familia plebeya que derivaba su nomen y origen de la mítica Mamilia, hija del fundador legendario de Tusculum (Telégono, hijo de Ulises y Circe). Los Mamilii se dividian en tres familias, con los cognomina Turrinus, Vitulus y Limetanus; las dos primeras eran las más antiguas e importantes. 
El tresvir monetalis de este denario era probablemente hijo de C. Mamilius Limetanus, tribuno de la plebe en el 109 a.C. Este instaló tribunales con jueces de rango ecuestre para investigar posibles culpables de colaboración con Jugurta. Varios prominentes senadores, en su mayoría con antecedentes contrarios a los Gracos, fueron condenados. También aprobó una ley que regulaba los límites de las tierras públicas; de ahí su cognomen Limetanus.
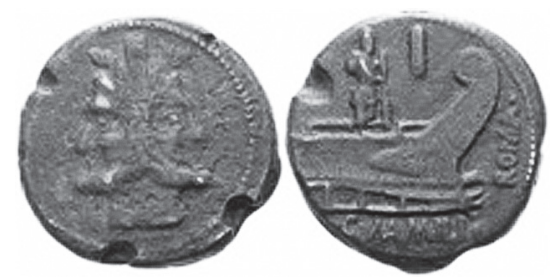

República Romana. L Mamilius. As. 189-180 a.C. 32 mm. 30 gr. Cabeza bifronte de Jano. Rx: C MAMILI ROMA. Ulises en la proa de un navío.

\section{AJAX HIJO DE TELAMÓN}

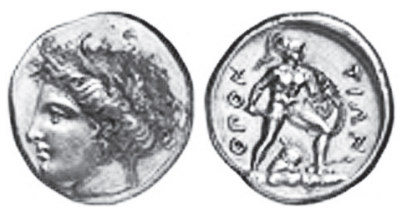

Lócride Opuntia. Ca. 382-356 a.C. AR estátera. 12.01g.

Cabeza de Perséfone hacia la izquierda. Rx: OПONTI $\Omega$ N Ajax avanzando hacia la derecha con casco, escudo y espada. Posiblemente defendiendo las armas de Patroclo (casco en el suelo) 


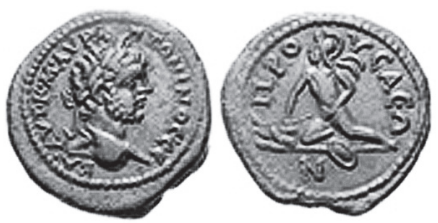

Prusas bajo el Olimpo (Bitinia). Caracalla. 198-217 d.C. AE 25mm, 9.51

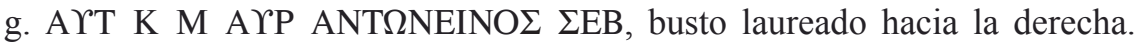
Rx: ПPO $\Sigma A E \Omega N$. Ajax cayendo sobre su espada apoyada en unas piedras; escudo abajo.

\section{TEUCRO, HERMANO DE AJAX HIJO DE TELAMÓN}

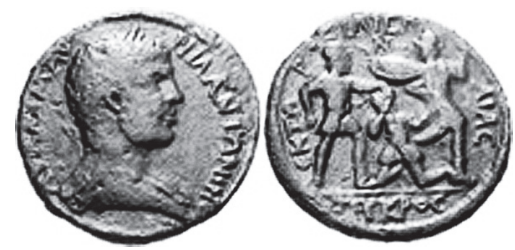

Ilión (Tróade). Caracalla. 198-217 d.C. 32mm.

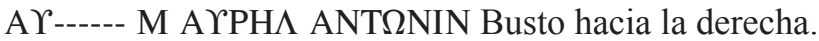

Rx: EKT $\Omega$ P I IIE $\Omega$ N AIA $\Sigma$ TEYKPO $\Sigma$ Héctor de pie con una roca que prepara para herir a Teucro, a quien agarra por el pelo. Teucro arrodillado con un arco cerca de su pie. En la derecha, Ajax corriendo hacia la izquierda blandiendo escudo y lanza.

\section{DIOMEDES}

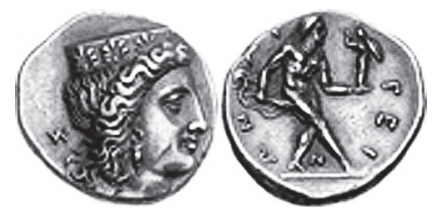

Argos (Argolis). Ca. 370-350 a.C. AR Dracma.

Cabeza de Hera hacia la derecha.

Rx: АРГЕIN $\Omega$ N Diomedes caminando hacia la derecha sosteniendo el Paladio. 


\section{FILOTECTES}

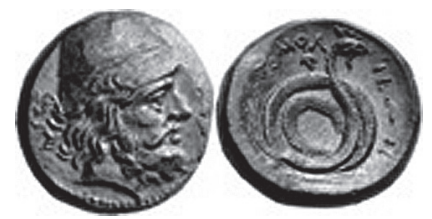

Homolion (Tesalia). Ca. 350 a.C. AE trichalkon (1/24 de dracma), 21mm, 7.46 g.

Cabeza de Filotectes hacia la derecha, con píleo cónico. Rx: OMO $\Lambda$-IE $\Omega N$ Serpiente hacia la derecha; atrás de su cabeza, racimo de uvas.

\section{PROTESILAO}

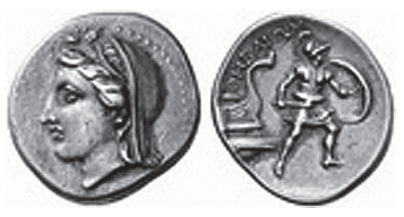

Tebas (Tesalia). Ca. 302-286 a.C. Dracma o tetraóbolo.

Cabeza velada (¿de ninfa?) hacia la izquierda.

Rx: $\Theta H B A I \Omega N$. Protesilao avanzando desde la proa de un navío.

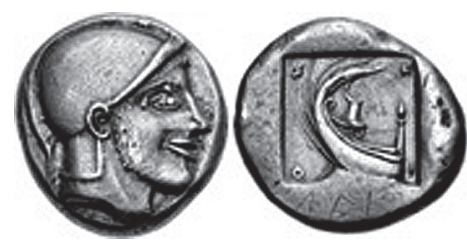

Escíone (Macedonia). Ca. 480-470 a.C. AR Tetradracma, 23mm, 16.57 g. Cabeza de Protesilao hacia la derecha, con casco ático; en la cimera ПРО[TЕ $\Sigma \Lambda]$ A $\Sigma$ (retrógrado).

Rx: Popa de galera, con aplaston, hacia la izquierda; $\Sigma$-K-I-O alrededor; todo en un cuadrado incuso. 


\section{Troyanos}

\section{HÉCTOR}
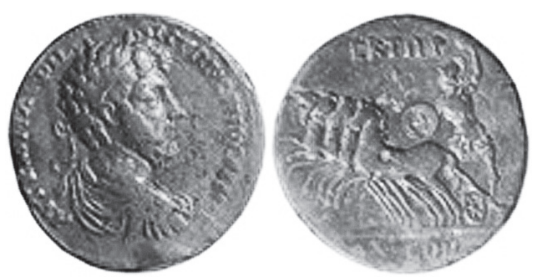

Ilión (Tróade) Marco Aurelio 161-180 d.C. AE 35mm 26.36g

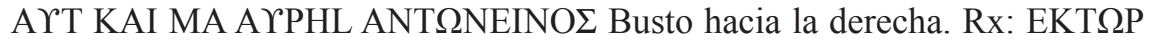
I $\Lambda$ IE $\Omega N$ Héctor conduciendo una cuadriga hacia la izquierda, armando con casco, coraza, escudo y lanza.

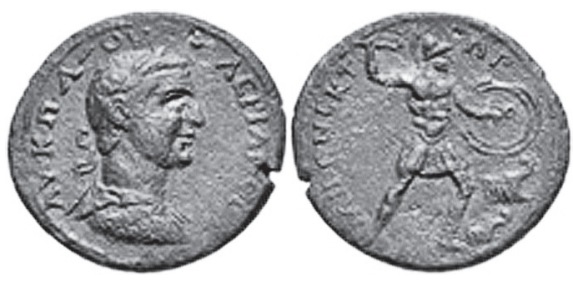

Ilión (Tróade) Valeriano I. 253-260 d.C. AE Medallón, 41mm, 27.02 g. Ar K. П A OrA $\Lambda E P I A N O \Sigma$. Busto hacia la derecha.

Rx: I $\Lambda$ I $\Omega$ N EKT $\Omega$ P Héctor, armando, avanzando hacia la derecha, proas de navíos a sus pies. 


\section{ENEAS Y ANQUISES}

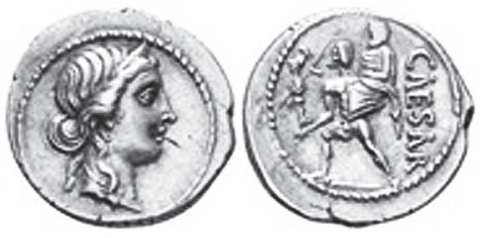

República Romana. Julio César. 47-46 a.C. AR denario, 18mm. Ceca militar en campaña con César en el norte de África.

Cabeza de Venus hacia la derecha. Rx: CAESAR Eneas avanzando hacia la derecha llevando a Anquises con la mano derecha y al Paladio con la izquierda. Al final de la República, la gens Iulia reivindicaba su descendencia de Venus a través de Eneas y Iulus (hijo de Ascanio o el propio Ascanio), rey de Alba Longa, antepasado de Rómulo y Remo.
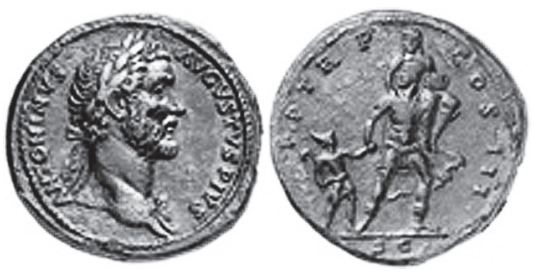

Imperio Romano. Antonino Pío. 140-144 d.C. AE sestercio. 26.52g. ANTONINVS AVGVSTVS PIVS Busto hacia la derecha. Rx: PP TPP COS III SC Eneas llevando a Anquises en el hombro y tomando la mano de Ascanio. 


\section{VI.- Otros hechos vinculados a las dos epopeyas}

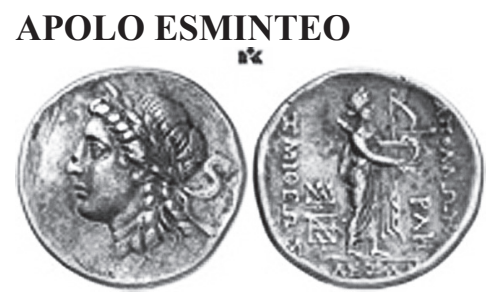

Alejandría (Tróade). Tetradracma, año real 138 (163 a.C.). 13,61 g. Cabeza de Apolo hacia la izquierda, con corona de laurel. Rx: АПО $\Lambda \Lambda \Omega N$

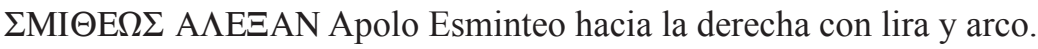

En el canto I de la Ilíada, el sacerdote Crises lo invoca para que vengue la ofensa que le hizo Agamenón cuando fue a rescatar a su hija.

\section{AQUILES MATA A PENTESILEA}
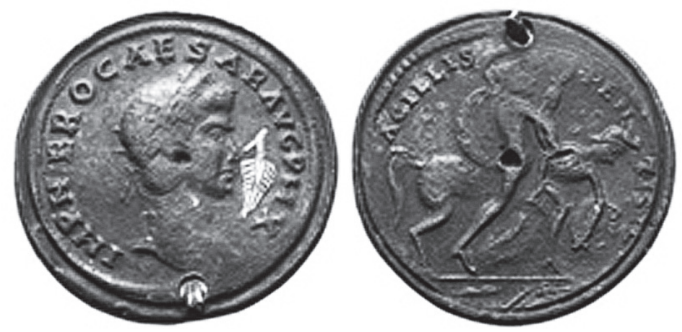

Imperio Romano. Æ contorniato, finales del siglo IV d.C.

IMP NERO CAESAR AVG P M X (sic), Cabeza de Nerón hacia la derecha, rama de palmera en plata a la derecha. Rx: ACILLIS PENTISILEA, Aquiles, con casco, espada y escudo, avanzando hacia la derecha y golpeando a Pentesilea para matarla; caballo atrás y armas de la caída en exergo.

Según Quinto de Esmirna (I, 42-47), luego de la muerte de Héctor, doce amazonas llegaron a Troya para apoyar a los sitiados; eran guiadas por su reina Pentesilea. 


\section{ODISEO SACRIFICA UN ANIMAL ANTES DE DESCENDER AL HADES}

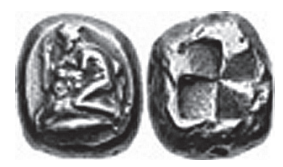

Cícico (Misia). Ca. 450-330 A.C. Electrón, estátera, 15.5mm, 15.93 g. Hombre adulto desnudo, excepto por el petasos y el manto atado al cuello, sacrificando un carnero. Rx: Cuadrado cuadripartito incuso.

La interpretación del hombre como Odiseo es debatida. Otro personaje que frecuentemente aparece haciendo un sacrifico es Frixo, pero es un joven.

\section{EL JARDÍN DE ALCÍNOO}

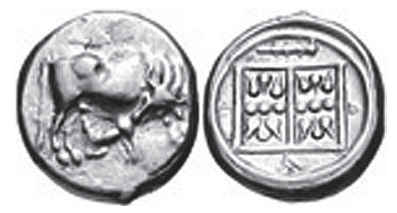

Dirraquio (Iliria). Ca. 340-280 BC. AR estátera, 20mm, 10.95 g.

Vaca hacia la derecha con la cabeza hacia abajo; ternero alimentándose. Rx: Diseño geométrico con mazo encima y $\Delta \Upsilon \mathrm{P}$ alrededor.

Algunos autores consideran que los elementos del centro del diseño son flores y que el conjunto representa el plano del jardín de Alcínoo o las puertas que conducen a él. El argumento se basa que la mítica Feacia era la antigua Córcira, isla que colonizó a Dirraquio. 


\section{VII.- Conclusiones}

Las monedas presentadas reflejan, por su variedad temática y su dispersión geográfica y temporal, el notable interés por los temas homéricos que se mantuvo sostenidamente durante la antigüedad clásica, pasando inalterado de Grecia a Roma. En efecto, las monedas reseñadas muestran la pervivencia del mundo de los dioses y héroes homéricos por más de 800 años, desde la estátera de Cícico del siglo VI o V a.C. con la imagen de la sirena hasta el medallón de Valeriano I de mediados del siglo III d.C. con un reverso que muestra a Héctor atacando a las naves aqueas. Recién a partir de la dinastía de Constantino el Grande, en la primera mitad del siglo IV d.C., desaparecen de la numismática las imágenes provenientes del mundo pagano $\mathrm{y}$, entre ellas, las vinculadas al ciclo homérico.

La Ilíada y la Odisea continuaron siendo leídas con interés durante todo ese período y formaron parte de los textos empleados para educar a la juventud. Sus manuscritos fueron copiados extensamente y, por ello, fueron de los textos de los que más copias sobrevivieron hasta la masificación de la imprenta.

También merece ser destacada la elevada calidad artística de los cuños utilizados. En efecto, quienes los confeccionaban solían ser artistas de la glíptica (tallado de piedras duras para anillos y piezas artísticas), con una estrecha relación con la estatuaria de la época. Ello se constata en las imágenes de personas (por ejemplo, bustos de los emperadores del apogeo del imperio, como Antonino Pío), de animales (lechuza, caballo o vaca), seres mitológicos (sirenas) o dioses (Zeus y Hera de la ceca de Olimpia). Muchas de las monedas más bellas incluidas en esta reseña son consideradas obras de arte en sí mismas, como el Dionisos de Naxos o el Poseidón del reinado de Demetrio Poliorcetes.

La moneda antigua se realizaba con grandes relieves y con cierta libertad creativa de los grabadores de sus cuños. Ello desapareció en las piezas del Bajo Imperio, bizantinas y medievales, y solo vuelve a presentarse en la medalla renacentista. La confección industrial y la exigencia de que las monedas puedan apilarse (lo que redujo fuertemente los relieves permitidos) hizo que la moneda moderna tenga un carácter marcadamente menos artístico.

También debe destacarse la vitalidad económica de las ciudades griegas del oriente del Imperio que pudieron sostener procesos de acuñación como provincias romanas o entidades semiautónomas. En las monedas provinciales, se encuentra una mayor variedad de temas mitológicos y locales que en las monedas imperiales, las que, sin embargo, generalmente superan a las primeras 
en lo que hace a la calidad de los cuños. La magnitud de las acuñaciones provinciales es particularmente notable al considerar que la gran mayoría de esas ciudades, casi todas excepto Antioquía y Alejandría, contaban a lo sumo con unos pocos miles de ciudadanos.

En la amplia área de cultura griega bajo dominación romana es notable la mantención de los diferentes temas de su pasado clásico en su moneda, entre ellos los referidos al ciclo homérico. Esto expresa el valor que los griegos de diferentes generaciones le dieron a ese componente de su cultura, la que lucharían por mantener más tarde en los siglos de la dominación otomana.

\section{BIBLIOGRAFÍA}

JENKINS, G.K. (1990) Ancient Greek Coins, segunda edición, Seaby.

KRAAY, C. M. (1976) Archaic and Classical Greek Coins, University of California Press.

MØRKHOLM, O. (1991) Early Hellenistic Coinage from the accession of Alexander to the Peace of Apamea (336-188 B.C.), Cambridge University Press.

SAYLES, W. G. (1997) Ancient Coin Collecting, Krause Publications.

Vol. II (Numismatic Art of the Greek World)

Vol. III (The Roman World-Politics and Propaganda)

Vol. IV (Roman Provincial Coins).

SEAR, D. R. (1978), Greek Coins and their values, segunda edición, Seaby, Londres.

--- (1996) Roman Coins and their values, cuarta edición, Seaby, Londres.

--- (1995) Greek Imperial Coins and their value. The local coinages of the

Roman Empire, Seaby, Londres.

SUTHERLAND, C.H.V. (1974) Roman Coins, Putman, New York.

Imágenes de monedas tomadas de:

Classical Numismatic Group/Research

https://www.cngcoins.com/Coins_sold.aspx

CoinArchives

https://www.coinarchives.com/a/

VCoins

https://www.vcoins.com/en/coins/ancient-2.aspx 